\title{
MICROMECHANICS OF CORROSION CRACKING IN REINFORCED CONCRETE BY AE
}

\author{
F. Uddin A.K.M. and M. Ohtsu \\ Graduate School of Science and Technology, Kumamoto University, Kumamoto 860-8555, Japan
}

\begin{abstract}
Nucleation of micro-cracking due to corrosion is detected and analyzed by AE-SiGMA procedure, by which crack kinematics of locations, types and orientations are quantitatively determined. Since these kinematical outcomes are obtained as three-dimensional (3-D) locations and vectors, 3-D visualization is developed by using VRML (Virtual Reality Modeling Language). The procedure is applied to corrosion cracking. Kinematics of micro-cracking due to corrosion are studied by numerical analysis BEM. Thus, relations between the stress intensity factors and cracking modes are investigated for different crack-patterns. It is confirmed that micromechanics of corrosion cracking are dominantly of mode-I failure associate with mixed-mode and mode-II.
\end{abstract}

\section{INTRODUCTION}

Corrosion of reinforcement in concrete is a major deterioration in reinforced concrete. For making decision on maintenance and repair, identification of cracking mechanisms due to corrosion is significantly important. Expansion caused by corrosion product generates micro-cracking, of which mechanisms can be investigated experimentally by acoustic emission (AE). AE-SiGMA procedure is developed as a powerful technique for moment tensor analysis of AE (Ohtsu [1]). Crack kinematics of locations, types and orientations are quantitatively determined (Ohtsu [2]). Because these kinematical outcomes are obtained as three-dimensional (3-D) locations and vectors, virtual reality modelling language (VRML) is applied. Thus, failure processes of corrosion cracking are clarified by using 3-D visualisation of AE-SiGMA procedure.

To investigate mechanisms of micro-cracking, numerical analysis by the boundary element method (BEM) is conducted on the basis of linear elastic fracture mechanics (LEFM). The maximum circumferential stress criterion based on LEFM was successfully applied to trace the crack extension (Farid and Ohtsu [3]). By employing the two-domain BEM, cracking mechanisms are evaluated from the stress intensity factors.

\section{EXPERIMENT}

To study crack patterns due to rebar corrosion in concrete, experiments were carried out. Concrete was made up of mixture as water $(\mathrm{W})$ :cement $(\mathrm{C})$ :sand $(\mathrm{S})$ : $\operatorname{gravel}(\mathrm{G})=0.5: 1.0: 2.41: 2.95$ by weight. The maximum size of aggregate was $20 \mathrm{~mm}$. Slump value and air content were $7.0 \mathrm{~cm}$ and $5.0 \%$, respectively. The dimensions of concrete specimens were $25 \mathrm{~cm} \times 25 \mathrm{~cm} \times 10 \mathrm{~cm}$. Two concrete specimens were casted with cover thickness $4 \mathrm{~cm}$. One is named specimen-A and other is secimen-B. To investigate other types of cracks than the surface crack, a precarcked notch with $1 \mathrm{~mm}$ width was created from the nearest side to the hole in specimen-B. This is because the surface crack is always nucleated prior to other cracks. To simulate corrosion cracking, an expansion test was conducted. In Figures 1 and 2, a circle of $3 \mathrm{~cm}$ diameter represents the location of the reinforcement where the expansion pressure is applied by dolomite paste and the expansion pressure was measured by using a pressure gauge embedded. Observed cracks after the test are 
found in the figures. Mechanical properties were obtained from cylindrical specimens at the age of 28days. Compressive strength was $37.9 \mathrm{MPa}$. The modulus of elasticity and Poisson's ratio were 29.7 $\mathrm{GPa}$ and 0.22 , respectively, which were applied to in BEM analysis.

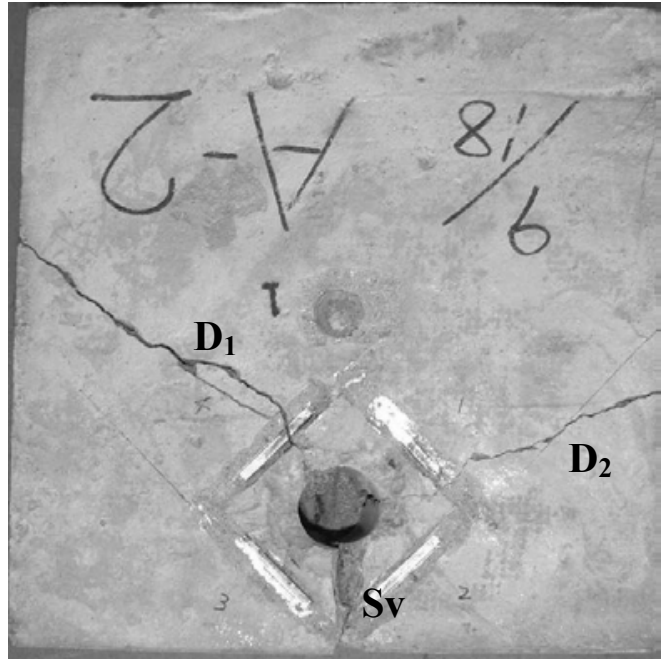

Figure 1: Observed cracks in specimen-A.

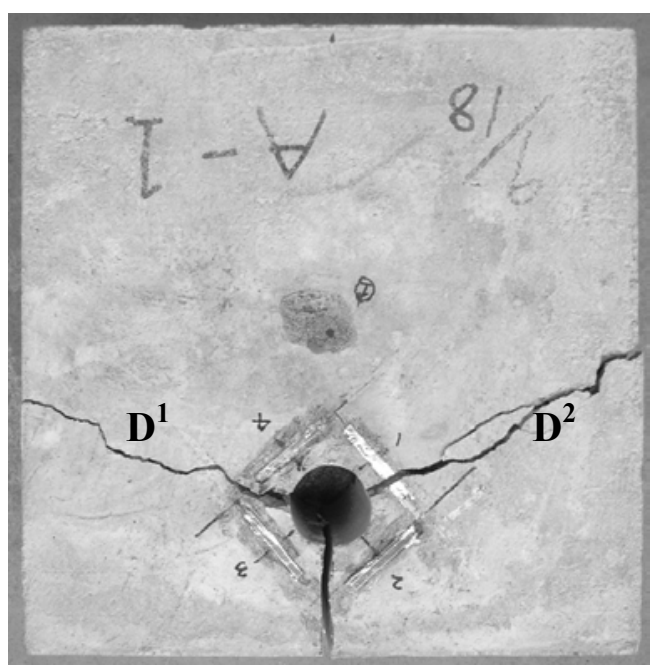

Figure 2: Observed cracks in specimen-B.

\section{CRACK KINEMATICS BY AE-SiGMA}

By taking into account only $\mathrm{P}$ wave motion of the far-field term of Green's function in an infinite space, displacement $\operatorname{Ui}(\mathrm{x}, \mathrm{t})$ of the first motion is obtained,

$$
\mathrm{Ui}(\mathrm{x}, \mathrm{t})=-1 /\left(4 \pi \rho v_{\mathrm{p}}{ }^{3}\right)\left(\mathrm{r}_{\mathrm{i}} \mathrm{r}_{\mathrm{p}} \mathrm{r}_{\mathrm{q}} / \mathrm{R}\right)(\mathrm{dS}(\mathrm{t}) / \mathrm{dt}) \mathrm{M}_{\mathrm{pq}} \text {. }
$$

Here $\rho$ is the density of the material and $v_{p}$ is the velocity of $P$ wave. $R$ is the distance between the source $y$ and the observation point $x$, of which direction cosine is $r=(r 1, r 2, r 3)$. $S(t)$ is the source-time function of crack motion. $\mathrm{M}_{\mathrm{pq}}$ is the moment tensor. Considering the effect of reflection at the surface and neglecting the source-time function, amplitude $\mathrm{A}(\mathrm{x})$ of the first motion is represented,

$$
\mathrm{A}(\mathrm{x})=\mathrm{Cs}(1 / \mathrm{R}) \operatorname{Ref}(\mathbf{s}, \mathbf{r}) \mathrm{r}_{\mathrm{p}} \mathrm{M}_{\mathrm{pq}} \mathrm{r}_{\mathrm{q}},
$$

where $\mathrm{Cs}$ is the calibration coefficient including material constants in eqn (1). $\mathbf{s}$ is the direction of the sensor sensitivity, and $\operatorname{Ref}(\mathbf{s}, \mathbf{r})$ is the reflection coefficient. Since the moment tensor $\mathrm{M}_{\mathrm{pq}}$ is symmetric, the number of independent components is six. Thus, multi-channel observation of the first motions at more than six channels is required to determine the moment tensor components by AE-SiGMA procedure. In the case of an isotropic material, the moment tensor $\mathrm{M}_{\mathrm{pq}}$, is defined as,

$$
\mathrm{M}_{\mathrm{pq}}=\left(\lambda \mathrm{l}_{\mathrm{k}} \mathrm{n}_{\mathrm{l}} \delta_{\mathrm{pq}}+\mu \mathrm{l}_{\mathrm{p}} \mathrm{n}_{\mathrm{q}}+\mu \mathrm{l}_{\mathrm{q}} \mathrm{n}_{\mathrm{p}}\right) \Delta \mathrm{V}
$$

where $\lambda$ and $\mu$ are Lame's elastic constants. $\mathbf{l}$ is the unit direction vector and $\mathbf{n}$ is the unit normal vector to the crack surface as shown in Figure $3 . \Delta \mathrm{V}$ is the crack volume. The classification of a crack is performed by the eigenvalue analysis of the moment tensor. Setting the ratio of the maximum shear contribution as $\mathrm{X}$, three eigenvalues of the shear crack become $\mathrm{X}, 0,-\mathrm{X}$. Likewise, the ratio of the maximum deviatric tensile component is set as $\mathrm{Y}$ and the isotropic tensile as $\mathrm{Z}$. It is assumed that the principal axes of the shear crack are identical to those of the tensile crack. Then, the eigenvalues of the moment tensor for a general case are represented by the combination of the shear crack and the tensile crack. Because relative values are determined in AE-SiGMA procedure, 
three eigenvalues $E_{1}, E_{2}$ and $E_{3}$ are normalized and decomposed as,

$$
1.0=X+Y+Z, E_{2} / E_{1}=0-0.5 Y+Z \text {, and } E_{3} / E_{1}=-X-0.5 Y+Z \text {, }
$$

where $\mathrm{X}, \mathrm{Y}$, and $\mathrm{Z}$ denote the shear ratio, the deviatric tensile ratio, and the isotropic tensile ratio, respectively. In the present analysis, AE sources of which the shear ratios $\mathrm{X}<0.4$ are classified into tensile cracks. Sources of $\mathrm{X}>0.6$ are classified into shear cracks. Sources, of which $\mathrm{X}$ ratios are between $40 \%$ and $60 \%$, are referred to as the mixed mode. Figure 4 shows the geometry among the eigenvectors $\mathbf{e}_{1}$ and $\mathbf{e}_{3}$, normal to crack surface $\mathbf{n}$ and crack motion direction $\mathbf{l}$. Three eigenvectors are $\mathbf{e}_{\mathbf{1}}=\mathbf{l}+\mathbf{n}, \mathbf{e}_{2}=\mathbf{l x n}$, and $\mathbf{e}_{3}=\mathbf{l}-\mathbf{n}$. Vectors $\mathbf{l}$ and $\mathbf{n}$ can be recovered from the following relations,

$$
\mathbf{l}=\left[\left(2+2 \mathrm{l}_{\mathrm{k}} \mathrm{n}_{\mathrm{k}}\right)^{1 / 2} \mathbf{e}_{\mathbf{1}}+\left(2-2 \mathrm{l}_{\mathrm{k}} \mathrm{n}_{\mathrm{k}}\right)^{1 / 2} \mathbf{e}_{3}\right] / 2, \mathbf{n}=\left[\left(2+2 \mathrm{l}_{\mathrm{k}} \mathrm{n}_{\mathrm{k}}\right)^{1 / 2} \mathbf{e}_{\mathbf{1}}-\left(2-2 \mathrm{l}_{\mathrm{k}} \mathrm{n}_{\mathrm{k}}\right)^{1 / 2} \mathbf{e}_{\mathbf{3}}\right] / 2 .
$$

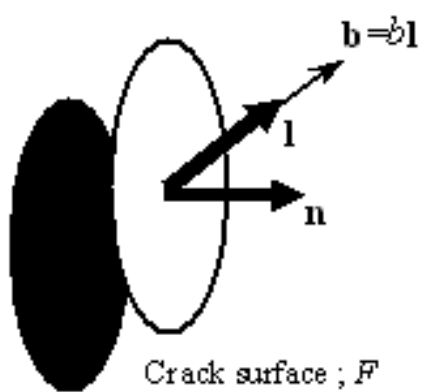

Figure 3: Modelling of a micro-crack.

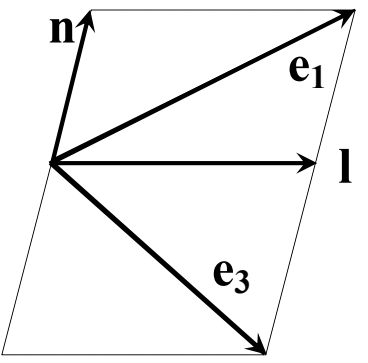

Figure 4: Eigenvectors by moment tensor analysis.

\section{VISUALISATION OF MICRO-CRACKING}

By conventional AE-SiGMA procedure, classification of cracks is made by symbols, whereas crack orientation is not easily recognized as 2-D projection. In this respect, VRML is introduced, as crack models of tensile, mixed-mode and shear are given in Figure 5. For specimen-A, 3-D visualization of AE-SiGMA procedure is shown in Figure 6. Shear cracks, tensile cracks and mixed-mode cracks are intensely observed near concrete cover, corresponding to the surface crack. The surface crack Sv, the diagonal cracks $\mathrm{D}_{1}$ and $\mathrm{D}_{2}$ start to initiate and extend. It is found that the surface cracks $\mathrm{Sv}$ is first nucleated and then the diagonal cracks $D_{1}$ and $D_{2}$ follow. 3-D visualization of AE-SiGMA procedure of specimen-B is shown in Figure 7. Shear cracks, tensile cracks and mixed-mode cracks are intensely observed corresponding to the diagonal cracks $\mathrm{D}^{1}$ and $\mathrm{D}^{2}$ in Figure 2 because of a pre-cracked notch is existed. Cracks distribute widely, corresponding to completion of the diagonal cracks.

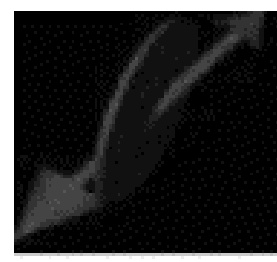

Shear crack

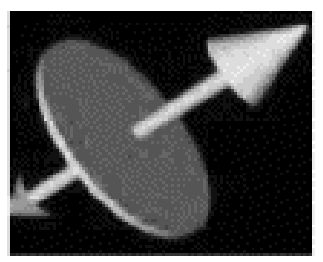

Tensile crack

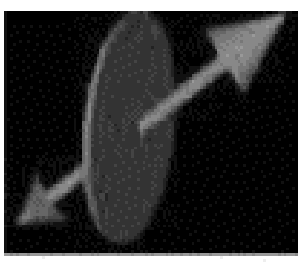

Mixed-mode crack

Figure 5: VRML models for tensile, shear, and mixed-mode cracks.

\section{ANALYTICALY MODEL}

Traces of the surface crack and the diagonal cracks are analyzed by BEM in a similar manner to the previous research (Farid and Ohtsu [3]). Initial two-domain elements are stitched at the interface jointing the initial crack tip with the final point. All boundary meshes are of $5 \mathrm{~mm}$ long. 
Because expansive agent was employed in the experiment for producing expansive pressure. In BEM analysis, three types of expansive pressure are taken into consideration to simulate the expansion of corrosive products. These are uniform pressure, horizontal pressure and vertical pressure. The stress intensity factors $\mathrm{K}_{\mathrm{I}}$ (mode I) and $\mathrm{K}_{\mathrm{II}}$ (mode II) are determined from relative displacements at the crack-tip elements by Smith's one-point formula. The direction of the maximum tangential stress $\theta$ is determined from the maximum circumferential stress by Erdogan-Sih criterion (Erdogan and Sih [4]).

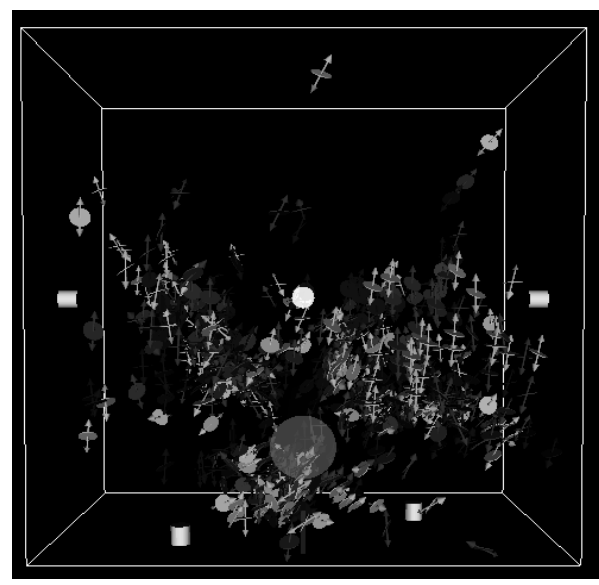

Figure 6: AE-SiGMA analysis visualised results of the specimen-A.

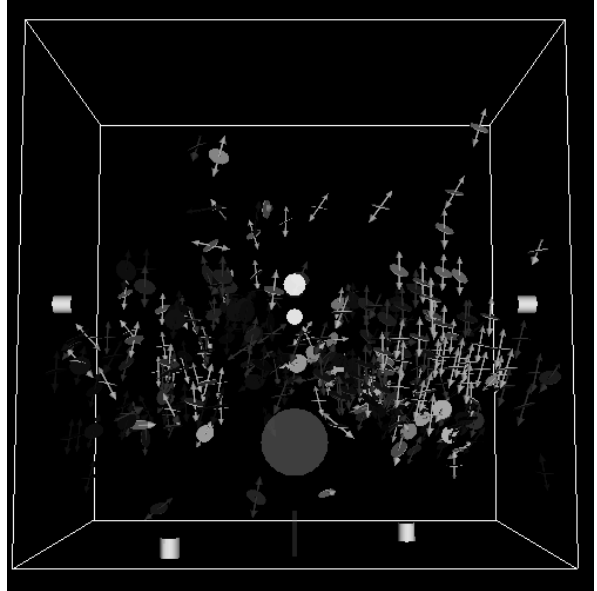

Figure 7: AE-SiGMA analysis visualised results of the specimen-B.

\section{IDENTIFIED MICROMECHANICS FOR CORROSION CRACKING}

Results analyzed by AE-SiGMA procedure are compared with those of BEM analysis. The dimensionless stress intensity factors $\mathrm{K}_{\mathrm{I}} / \mathrm{K}_{\mathrm{IC}}$ and $\mathrm{K}_{\mathrm{II}} / \mathrm{K}_{\mathrm{IC}}$ (Carpinterri [5]) are calculated at each step by substituting angles of micro-cracking from BEM analysis and from the experiment.

\subsection{Surface crack Sv in specimen-A}

The surface crack Sv is analyzed by BEM and compared with the actual crack trace in experiment. Through all the cracking steps, crack trace due to vertical pressure is the closest to the actual trace in the experiment out of any other pressure distributions. $\mathrm{K}_{\mathrm{I}} / \mathrm{K}_{\mathrm{IC}}$ and $\mathrm{K}_{\mathrm{II}} / \mathrm{K}_{\mathrm{IC}}$ are calculated as shown in Figure 8. In the beginning of crack extension, $\mathrm{K}_{\mathrm{I}} / \mathrm{K}_{\mathrm{IC}}$ is nearly equal to 1.0 , so the pure mode I fracture occurs. $\mathrm{K}_{\mathrm{II}} / \mathrm{K}_{\mathrm{IC}}$ obtained form the crack trace at front face increases gradually and in the middle stage of crack extension $\mathrm{K}_{\mathrm{II}} / \mathrm{K}_{\mathrm{IC}}$ is greater than $\mathrm{K}_{\mathrm{I}} / \mathrm{K}_{\mathrm{IC}}$, where shear cracks could occur. Active nucleation of shear cracks is found in the results of AE-SiGMA procedure in Figure 6. It is concluded that for micro-cracking of the surface crack, tensile cracks eventually
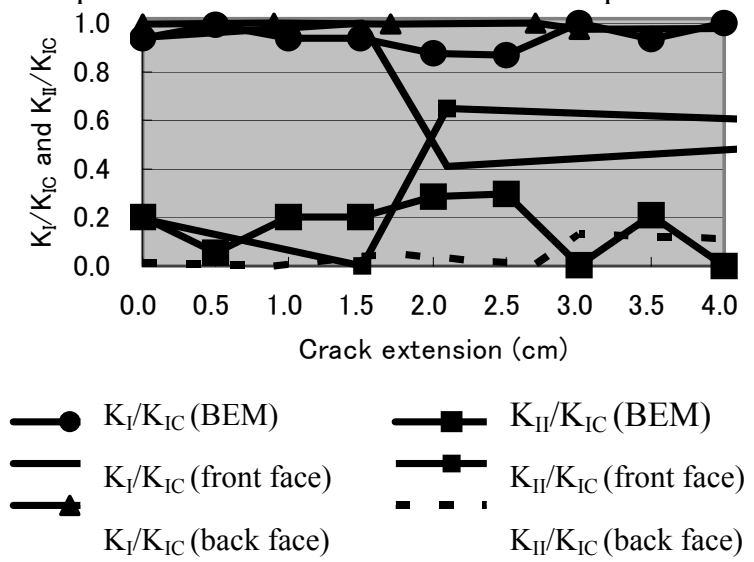

Figure 8: $\mathrm{K}_{\mathrm{I}} / \mathrm{K}_{\mathrm{IC}}$ and $\mathrm{K}_{\mathrm{II}} / \mathrm{K}_{\mathrm{IC}}$ during micro-cracking for surface crack Sc in specimen-A. 
dominate shear cracks.

6.2 Diagonal crack $\mathrm{D}_{1}$ in specimen-A

The diagonal crack $D_{1}$ is analyzed, simulating the crack extension after the surface crack. Crack trace due to uniform pressure is the closest to the actual traces $\mathrm{K}_{\mathrm{I}} / \mathrm{K}_{\mathrm{IC}}$ and $\mathrm{K}_{\mathrm{II}} / \mathrm{K}_{\mathrm{IC}}$ are calculated as shown in Figure 9. In only the beginning of crack extension, $\mathrm{K}_{\mathrm{I}} / \mathrm{K}_{\mathrm{IC}}$ is nearly equal to 1.0 . Then, $\mathrm{K}_{\mathrm{II}} / \mathrm{K}_{\mathrm{IC}}$ increases gradually and in the middle stage $\mathrm{K}_{\mathrm{II}} / \mathrm{K}_{\mathrm{IC}}$ becomes almost equal to $\mathrm{K}_{\mathrm{I}} / \mathrm{K}_{\mathrm{IC}}$. Also, $\mathrm{K}_{\mathrm{I}} / \mathrm{K}_{\mathrm{IC}}$ values are mostly lower than those of the surface crack. As confirmed by 3-D VRML visualization of AE-SiGMA procedure in Figure 6, shear and mixed-mode cracks are intensely generated. It is concluded that for micro-cracking of the diagonal crack $\mathrm{D}_{1}$, tensile cracks not only are dominant but also shear and mixed-mode cracks are active.

6.3 Diagonal crack $\mathrm{D}_{2}$ in specimen-A

The diagonal crack $\mathrm{D}_{2}$ is analyzed through all the cracking steps, crack trace due to uniform pressure is the closest to the actual traces for the both the front face and the back face of the crack. Analyzed $\mathrm{K}_{\mathrm{I}} / \mathrm{K}_{\mathrm{IC}}$ and $\mathrm{K}_{\mathrm{II}} / \mathrm{K}_{\mathrm{IC}}$ are shown in Figure 10. In the beginning of crack extension, $\mathrm{K}_{\mathrm{I}} / \mathrm{K}_{\mathrm{IC}}$ is again nearly equal to 1.0 . The values of $\mathrm{K}_{\mathrm{I}} / \mathrm{K}_{\mathrm{IC}}$ are larger than those of the diagonal crack $\mathrm{D}_{1}$, but the values of $\mathrm{K}_{\mathrm{II}} / \mathrm{K}_{\mathrm{IC}}$ are smaller. Still the values of $\mathrm{K}_{\mathrm{I}} / \mathrm{K}_{\mathrm{IC}}$ are smaller than those of the surface crack Sv. This implies that the mechanisms of the diagonal crack $\mathrm{D}_{2}$ are in between those of cracks $\mathrm{Sv}$ and $\mathrm{D}_{1}$.

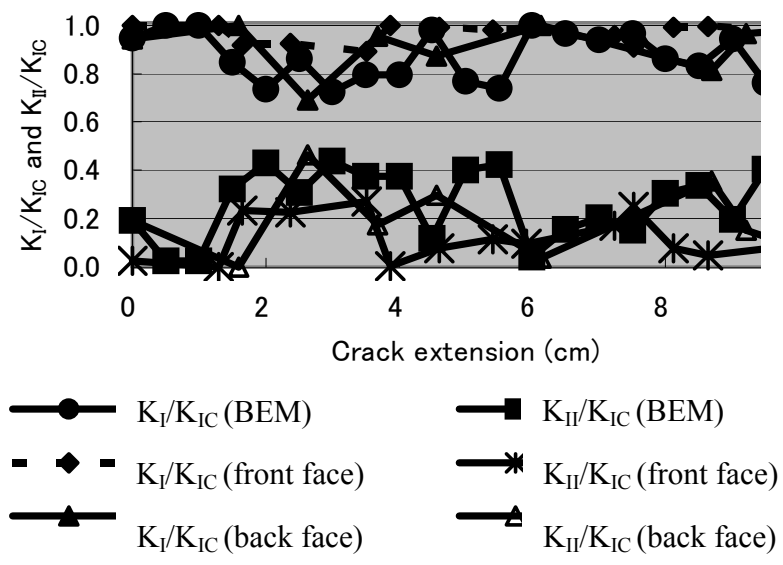

Figure 9: $\mathrm{K}_{\mathrm{I}} / \mathrm{K}_{\mathrm{IC}}$ and $\mathrm{K}_{\mathrm{II}} / \mathrm{K}_{\mathrm{IC}}$ during micro-cracking For diagonal crack $\mathrm{D}_{1}$ in specimen-A.
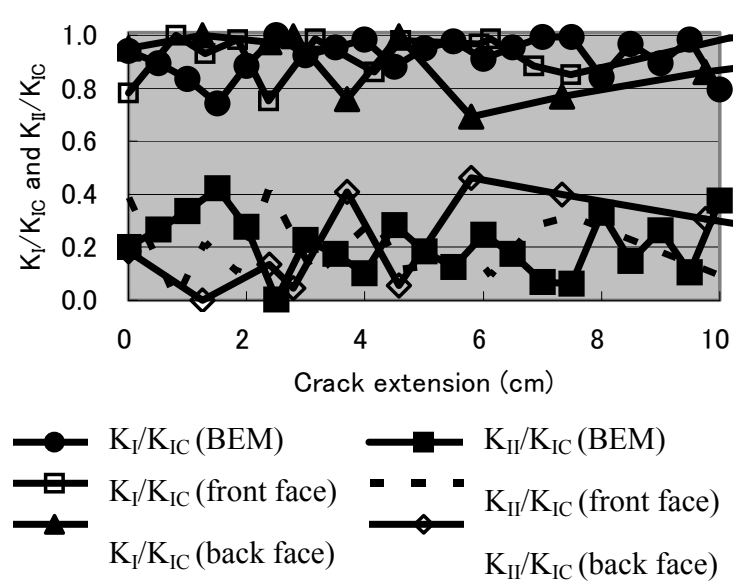

Figure 10: $\mathrm{K}_{\mathrm{I}} / \mathrm{K}_{\mathrm{IC}}$ and $\mathrm{K}_{\mathrm{II}} / \mathrm{K}_{\mathrm{IC}}$ during micro-cracking for diagonal crack $\mathrm{D}_{2}$ in specimen-A.

\subsection{Diagonal crack $\mathrm{D}^{1}$ in specimen-B}

Through all the cracking steps, crack trace due to uniform pressure is the closest to the actual trace in the experiment. Analyzed $\mathrm{K}_{\mathrm{I}} / \mathrm{K}_{\mathrm{IC}}$ and $\mathrm{K}_{\mathrm{II}} / \mathrm{K}_{\mathrm{IC}}$ are shown in Figure 11. In the beginning of the crack extension, $\mathrm{K}_{\mathrm{I}} / \mathrm{K}_{\mathrm{IC}}$ is again nearly equal to 1.0 . Sometimes $\mathrm{K}_{\mathrm{II}} / \mathrm{K}_{\mathrm{IC}}$ slightly increases. It is concluded that for micro-cracking of the diagonal crack $\mathrm{D}^{1}$, tensile cracks are dominant but mixed-mode cracks are sometimes active as confirmed by 3-D VRML visualization in Figure 7.

\subsection{Digonal crack $\mathrm{D}^{2}$ in specimen-B}

Through all the cracking steps, crack trace due to uniform pressure is the closest to the actual trace in the experiment. Analyzed $\mathrm{K}_{\mathrm{I}} / \mathrm{K}_{\mathrm{IC}}$ and $\mathrm{K}_{\mathrm{II}} / \mathrm{K}_{\mathrm{IC}}$ are shown in Figure 12. In the beginning of the 
crack extension, $\mathrm{K}_{\mathrm{I}} / \mathrm{K}_{\mathrm{IC}}$ is nearly equal to $0.8 . \mathrm{K}_{\mathrm{II}} / \mathrm{K}_{\mathrm{IC}}$ becomes greater than $\mathrm{K}_{\mathrm{I}} / \mathrm{K}_{\mathrm{IC}}$ in the beginning at the front face and in the middle at the back face of micro-cracking. It is concluded that for micro-cracking of digonal crack $\mathrm{D}^{2}$, tensile cracks are not only dominant but also shear and mixed-mode cracks are fairly active as confirmed by 3-D VRML visualization in Figure 7.

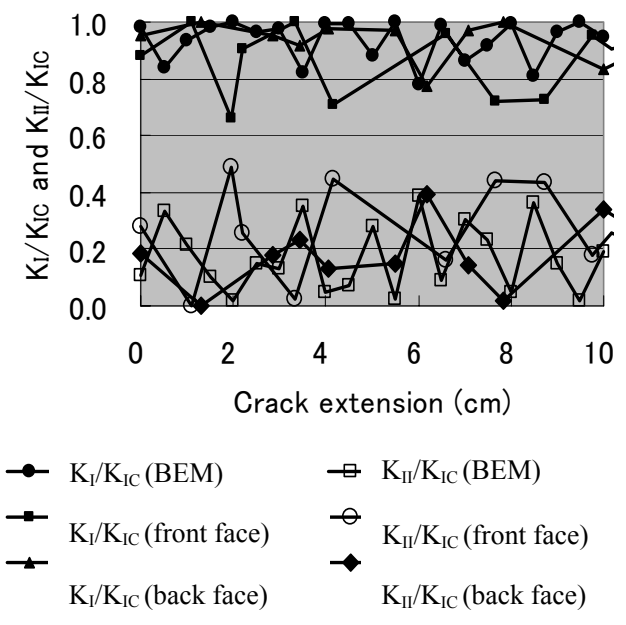

Figure 11: $\mathrm{K}_{\mathrm{I}} / \mathrm{K}_{\mathrm{IC}}$ and $\mathrm{K}_{\mathrm{II}} / \mathrm{K}_{\mathrm{IC}}$ during micro-cracking for diagonal crack $\mathrm{D}^{1}$ in specimen-B.
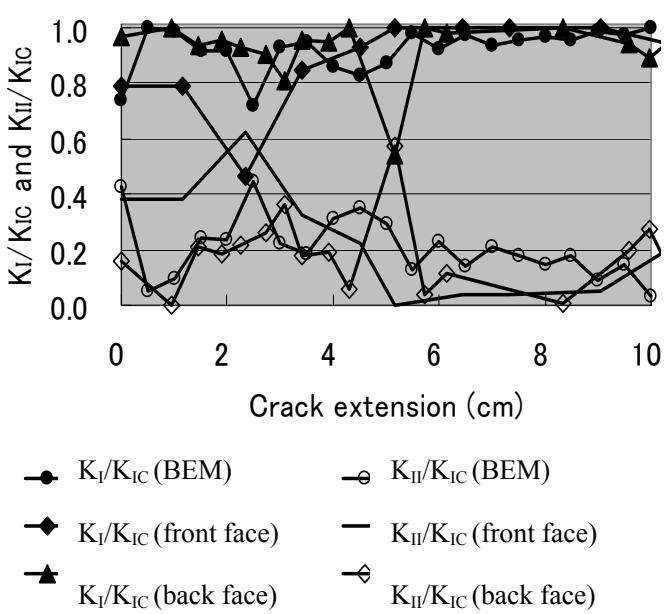

Figure 12: $\mathrm{K}_{\mathrm{I}} / \mathrm{K}_{\mathrm{IC}}$ and $\mathrm{K}_{\mathrm{II}} / \mathrm{K}_{\mathrm{IC}}$ during micro-cracking for diagonal crack $\mathrm{D}^{2}$ in specimen-B.

\section{CONCLUSION}

Micro-cracks due to rebar corrosion in concrete is studied analytically and experimentally. A two-domain BEM is applied to the mixed-mode crack extension based on the maximum circumferential stress criterion. Traces of the surface crack and the diagonal cracks in the arbitrary direction are analyzed. These cracks were produced by employing expansive agent into concrete specimen. Micro-cracking mechanisms are investigated by BEM and confirmed by AE-SiGMA procedure with 3-D VRML. Depending on the crack types, contributions of mode I and mode II are varied during crack propagation. Micromechanics of corrosion cracking in concrete is mostly of mode I fracture along with mode II and the mixed-mode.

\section{REFERENCES}

1. Ohtsu, M., Simplified Moment Tensor Analysis and Unified Decomposition of AE source, Journal of Geophys. Res.; 96, pp.6211-6221, 1991.

2. Ohtsu, M., Source Mechanism and Waveform Analysis of Acoustic Emission in Concrete, Journal of AE, 2(1), 103-112, 1982.

3. Farid Uddin, A.K.M., and Ohtsu, M., BEM Analysis of Mixed-Mode Crack Propagation due to Corrosion of Reinforcement in Concrete, Journal of Materials, Concrete Structures and Pavements, JSCE, No.704/V-55, pp.271-280, 2002.

4. Erdogan, F., and Sih, G.C., On the Crack Extension in Plates under Plane Loading and Transverse Shear, Journal of Basic Eng., No.12, pp.519-527, 1963.

5. Carpinterri, A., Mechanical Damage and Crack Growth in Concrete, Martinus Nijhoff Publishers, Dordrecht, the Netherlands, 1986. 